\title{
Case study of the effectiveness of passive grease trap for management on domestic kitchen waste water
}

\begin{abstract}
Household waste, generally known as trash or garbage is mostly includes food wastes, product packaging, and other miscellaneous inorganic wastes that are coming from domestic household. Grease waste such as oil and fats can contaminate water and also clot on pipes provoking blockages. Thus, waste water from kitchen sink need a proper way of filtration. Grease trap developed in this paper is viable in trapping the grease residue. The experiments have been conducted in controlled environment and the objectives are to investigate the effectiveness of grease trap by proving the existence of retention time and the expected ratio of collected water and oil during experiment process using a prototype model.
\end{abstract}

Keyword: Fat, oil and grease (FOG); Passive grease trap; Retention time 